\title{
Acute kidney injury in ECMO patients
}

\author{
Marlies Ostermann ${ }^{1^{*}}$ and Nuttha Lumlertgul ${ }^{1,2,3}$
}

\begin{abstract}
This article is one of ten reviews selected from the Annual Update in Intensive Care and Emergency Medicine 2021.

Other selected articles can be found online at https://www.biomedcentral.com/collections/annualupdate2021.

Further information about the Annual Update in Intensive Care and Emergency Medicine is available from https://ink. springer.com/bookseries/8901.
\end{abstract}

\section{Introduction}

Extracorporeal membrane oxygenation (ECMO) is a lifesaving therapy for patients with severe respiratory and/ or cardiovascular failure. There are two main configurations: (1) veno-arterial ECMO (VA-ECMO) in patients with refractory cardiogenic shock or combined cardiorespiratory failure, and (2) veno-venous ECMO (VVECMO) in patients with potentially reversible causes of respiratory failure. Over the past decade, use of ECMO has increased substantially in critical care units, emergency departments, interhospital transfers, operating rooms, and during cardiopulmonary resuscitation (CPR) [1].

The in-hospital mortality ranges from 21 to $37 \%$ in patients receiving VV-ECMO compared to $40-60 \%$ in patients treated with VA-ECMO [2-4]. Despite improving survival in recent years, adverse effects are common including acute kidney injury (AKI), infection, thrombosis, and bleeding [5]. AKI is a frequent complication among patients treated with ECMO, resulting in increased morbidity and mortality [6]. Understanding the impact of AKI, its contributing factors, and renal replacement therapy (RRT) is essential to inform clinical practice and design future studies for prevention and management of this high-risk group.

*Correspondence: Marlies.Ostermann@gstt.nhs.uk

${ }^{1}$ Department of Critical Care, King's College London, Guy's and St Thomas' NHS Foundation Trust, London, UK

Full list of author information is available at the end of the article

\section{Incidence of AKI in ECMO}

The reported incidence of AKI in patients treated with ECMO varies from 26 to $85 \%$ due to differences in patient characteristics, AKI definition, and clinical settings. The pooled estimated incidence of severe AKI requiring RRT is $45 \%$ [6]. AKI is more common in VA-ECMO than in VV-ECMO (61\% vs. $46 \%$ ) and is most often present on the day of ECMO cannulation [6, 7]. The Extracorporeal Membrane Oxygenation for Severe Acute Respiratory Distress Syndrome (EOLIA) and Conventional Ventilatory Support versus Extracorporeal Membrane Oxygenation for Severe Adult Respiratory Failure (CESAR) trials demonstrated a lower incidence of AKI and use of RRT in patients receiving VV-ECMO compared with standard treatment [2].

\section{Pathophysiology of AKI in ECMO}

The underlying mechanisms of AKI in patients treated with ECMO are complex and multifactorial (Table 1).

\section{Patient factors and critical illness}

Prior to ECMO initiation, hemodynamic instability, low cardiac output, high intra-thoracic pressure, exposure to nephrotoxic agents, severe hypoxemia, hypercapnia, systemic inflammation/immune-mediated effects, and neurohormonal dysregulation can contribute to AKI [8]. In patients with heart failure, cardiac dysfunction, increased intra-abdominal pressure (IAP), and renal congestion contribute to impaired renal blood flow and cardiorenal syndrome [9]. AKI might also occur in the context 
Table 1 Risk factors for acute kidney injury (AKI) during extracorporeal membrane oxygenation (ECMO)

\begin{tabular}{|c|c|}
\hline Factors & Pathophysiological mechanisms \\
\hline Patient-related variables & $\begin{array}{l}\text { Hypoperfusion } \\
\text { Loss of autoregulation } \\
\text { Hypoxia } \\
\text { Hypercapnia } \\
\text { Nephrotoxins } \\
\text { Systemic inflammation } \\
\text { Cardiorenal syndrome } \\
\text { Increased intrathoracic pressure } \\
\text { Increased intra-abdominal pressure } \\
\text { Neuro-hormonal effects }\end{array}$ \\
\hline IMV-related factors & Biotrauma \\
\hline ECMO-related factors & PEEP \\
\hline Hemodynamic variables & $\begin{array}{l}\text { Continuous flow (VA-ECMO) } \\
\text { Ischemia-reperfusion injury }\end{array}$ \\
\hline Hormonal variables & $\begin{array}{l}\text { RAAS dysregulation } \\
\text { ANP downregulation }\end{array}$ \\
\hline Circuit-related factors & $\begin{array}{l}\text { Blood shear stress } \\
\text { Rhabdomyolysis } \\
\text { Hemolysis and oxidative stress } \\
\text { Embolism } \\
\text { Aortic dissection }\end{array}$ \\
\hline Systemic inflammation & $\begin{array}{l}\text { Systemic inflammation } \\
\text { Renal macro/microcirculatory dysfunction } \\
\text { Bioincompatibility } \\
\text { Blood/air/surface interaction } \\
\text { Hypercoagulable state }\end{array}$ \\
\hline
\end{tabular}

$I M V$ invasive mechanical ventilation, $P E E P$ positive end-expiratory pressure, $V A$ veno-arterial, RAAS renin-angiotensin-aldosterone system, ANP atrial natriuretic peptide

of other critical illness-related complications including bleeding, limb ischemia, infection, and coagulopathy [8].

\section{Impact of mechanical ventilation}

Invasive mechanical ventilation is associated with altered hemodynamics and release of pro-inflammatory cytokines (e.g., tumor necrosis factor $[\mathrm{TNF}]-\alpha$, interleukin [IL]-1 $\beta$, IL-6 and IL-8) [10]. Plasma cytokine concentrations are predictive of AKI development and renal non-recovery [11]. The application of positive endexpiratory pressure (PEEP) has several beneficial effects for lung recruitment and decrease in left ventricular (LV) pre- and afterload. However, increasing PEEP and/ or tidal volumes may elevate intrathoracic pressure, reduce venous return, decrease cardiac output, and increase right ventricular (RV) afterload, resulting in elevated systemic venous pressure, venous congestion, and reduction of renal perfusion. In addition, fluid retention may develop as a result of activation of the sympathetic nervous system (SNS) and renin-angiotensin-aldosterone system (RAAS), and suppression of atrial natriuretic peptide (ANP) release [9]. Lung-protective ventilation limits lung injury and has potential to reduce the risk of AKI [12]. However, permissive hypoxia and hypercapnia might ensue and decrease renal blood flow [9].

\section{ECMO-related factors}

Following ECMO cannulation, an improvement in oxygenation helps restore the microcirculation in previously hypoxic and hypoperfused organs and tissues, often in association with a degree of ischemia-reperfusion injury and production of reactive oxygen species (ROS) [13]. Continuous flow during VA-ECMO reduces pulsatility, which may compromise renal cortical blood flow and upregulate the RAAS inducing systemic vasoconstriction [14]. Circuit-related factors contributing to the development of AKI include hemolysis, rhabdomyolysis from local ischemia, hemorrhage, renal microthrombosis, and cannula-related complications (e.g., malposition of the cannula leading to venous obstruction, cholesterol embolism following cannulation, aortic dissection) $[15,16]$. Hemolysis may occur due to a combination of shear stress from blood travelling through the blood pump, negative intra-circuit pressures, and contact with the non-biological and non-endothelialized surface of ECMO membranes [15]. This leads to elevated plasma free hemoglobin, release of free iron, oxidative stress, and filtered heme pigments causing tubular obstruction [17]. Blood exposure to artificial surfaces also induces the release of inflammatory cytokines, complement and leukocyte activation, and hypercoagulability. Finally, 74 although VA-ECMO improves oxygenation and peripheral circulation, limited LV off-loading combined with low ejection fraction can result in LV overdistension and worsening pulmonary edema.

\section{Risk factors for AKI}

Reported risk factors for AKI during ECMO are older age, pre-existing comorbidities (e.g., cirrhosis), post cardiotomy shock as indication for ECMO, late implantation of ECMO, reduced LV ejection fraction (LVEF), intraoperative transfusion, high lactate, high plasma free hemoglobin, increased bilirubin, and high neutrophil to lymphocyte ratio [18]. Red blood cell distribution width $>14.1 \%$, a marker of inflammation and anemia, has also been found to be associated with an increased risk of severe AKI [19]. During ECMO, high inotropic equivalents, ECMO pump speed, and ECMO duration are linked to AKI development [20]. Higher pump speeds are associated with hemolysis, leukocyte and platelet destruction, and complement activation [21]. To prevent heme pigment-associated AKI, pump revolutions/min (RPM) should be limited to safe levels to avoid excessive negative pressures. AKI patients who required RRT 
whilst receiving ECMO were more likely to be treated with VA-ECMO, had more organ dysfunction at the time of ECMO insertion, and required more transfusions [22].

\section{RRT and ECMO Indications}

Fluid overload is highly prevalent and associated with higher mortality and pro-longed ECMO duration [23]. According to a recent survey, fluid overload management (43\%) or prevention $(16 \%)$ are the predominant triggers for RRT initiation during ECMO, followed by AKI (35\%), and electrolyte disturbances (4\%) [24].

\section{Timing}

Theoretically, early initiation of RRT may help resolve fluid overload faster and achieve better sodium removal per unit volume than diuretics in ECMO patients. In general ICU patients, recent randomized controlled trials (RCTs) not only failed to demonstrate the survival benefits of early over standard initiation strategy, but also showed increased harm in the early-initiation group including an increased risk of dialysis dependence at 90 days and adverse events [25-27]. A post-hoc sub-analysis of The Artificial Kidney Initiation in Kidney Injury (AKIKI) trial in acute respiratory distress syndrome (ARDS) also demonstrated similar outcomes between early and standard initiation strategies [28]. Another study using propensity-score matching compared early versus late initiation of CRRT after ECMO (median time from ECMO to CRRT initiation 1 vs. 15 days) and found no difference in survival [29].

In light of the fact that serum creatinine, AKI stage and urine output are poor markers to guide initiation of RRT, the demand-capacity concept has been proposed as a method to guide the decision-making process. Accordingly, RRT should be considered if the degree of fluid overload and AKI-related metabolic derangements are likely to overwhelm the kidneys' capacity to compensate, and pharmacological measures (diuretic therapy, sodium bicarbonate) are unlikely to be effective [30]. The expert committee of the 21st Acute Dialysis Quality Initiative (ADQI) meeting concluded that there was no evidence of benefit for pre-emptive use of RRT in patients treated with ECMO [9]. Therefore, the decision to initiate RRT in patients receiving ECMO should be based on usual absolute and relative indications for critically ill patients.

\section{Modality}

RRT options include continuous RRT (CRRT), prolonged intermittent renal replacement therapy (PIRRT), intermittent hemodialysis (IHD), and peritoneal dialysis. Each modality has advantages and disadvantages (Table 2). CRRT and peritoneal dialysis are suitable for patients with hemodynamic instability although CRRT enables more precise fluid and electrolyte management. Meanwhile, PIRRT and IHD allow planned circuit downtime. It is possible to provide CRRT, PIRRT and IHD via integration into the ECMO circuit or separately. When choosing CRRT, any mode of clearance can be delivered, namely slow continuous ultra-filtration (SCUF), continuous veno-venous hemofiltration $(\mathrm{CVVH})$, continuous venovenous hemodialysis (CVVHD), and continuous venovenous hemodiafiltration (CVVHDF).

\section{Techniques}

There are three ways to provide RRT with ECMO: using an in-line hemofilter, connecting a RRT device to the ECMO circuit (integrated system), or using a separate

Table 2 Advantages and disadvantages of each renal replacement modality during extracorpo-real membrane oxygenation (ECMO)

\begin{tabular}{|c|c|c|}
\hline Modality & Advantages & Disadvantages \\
\hline IHD & $\begin{array}{l}\text { Integration in ECMO circuit possible } \\
\text { Reduced filter downtime } \\
\text { Lower costs than CRRT }\end{array}$ & $\begin{array}{l}\text { Need for more rapid fluid removal } \\
\text { Risk of hemodynamic instability } \\
\text { Disequilibrium syndrome }\end{array}$ \\
\hline PIRRT & $\begin{array}{l}\text { Integration in ECMO circuit possible } \\
\text { Reduced filter downtime } \\
\text { Lower costs than CRRT } \\
\text { Slower volume and solute removal than IHD }\end{array}$ & Risk of hemodynamic instability in high-risk patients \\
\hline CRRT & $\begin{array}{l}\text { Integration in ECMO circuit possible } \\
\text { Continuous fluid and solute removal } \\
\text { Allows more precise control of fluid balance } \\
\text { Better hemodynamic stability }\end{array}$ & $\begin{array}{l}\text { Patient immobilization } \\
\text { Increased risk of hypothermia } \\
\text { High costs }\end{array}$ \\
\hline PD & $\begin{array}{l}\text { Better hemodynamic stability } \\
\text { Technically simple } \\
\text { Lower cost } \\
\text { No addition of anticoagulation }\end{array}$ & $\begin{array}{l}\text { Less experience in adult patients } \\
\text { Requires specific intraperitoneal catheters } \\
\text { Risk of peritonitis } \\
\text { Risk of hyperglycemia } \\
\text { May interfere with diaphragmatic movements }\end{array}$ \\
\hline
\end{tabular}


Table 3 Advantages and disadvantages of RRT techniques during extracorporeal membrane oxygenation (ECMO) [31, 33]

\begin{tabular}{|c|c|c|}
\hline Techniques & Advantages & Disadvantages \\
\hline In-line hemofilter & $\begin{array}{l}\text { Low cost } \\
\text { Generates large volumes of UF } \\
\text { No need for separate anticoagulation } \\
\text { Small priming volume }\end{array}$ & $\begin{array}{l}\text { No pressure monitoring } \\
\text { Requires external infusion device to control UF and deliver replacement } \\
\quad \text { fluid } \\
\text { Less precise UF } \\
\text { Limited solute clearance } \\
\text { Flow turbulence and risk of hemolysis }\end{array}$ \\
\hline $\begin{array}{l}\text { Independent RRT } \\
\text { access (parallel } \\
\text { system) }\end{array}$ & $\begin{array}{l}\text { Allows fine-tune adjustment of solute and fluid removal } \\
\text { Able to provide RRT independent of ECMO } \\
\text { Allows use of regional anticoagulation } \\
\text { Simplified circuit changing without need for perfusionist } \\
\text { Mode of solute clearance not restricted }\end{array}$ & $\begin{array}{l}\text { Need for separate vascular access } \\
\text { Risk of mechanical and infectious complications } \\
\text { Higher extracorporeal blood volume } \\
\text { Technically more complex to manage two separate circuits }\end{array}$ \\
\hline $\begin{array}{l}\text { RRT connected } \\
\text { to ECMO circuit } \\
\text { (integrated } \\
\text { system) }\end{array}$ & $\begin{array}{l}\text { Allows fine-tune adjustment of solute and fluid removal } \\
\text { Mode of solute clearance not restricted } \\
\text { No need for separate vascular access } \\
\text { Avoids complications related to line insertion }\end{array}$ & $\begin{array}{l}\text { Pressure alarms (low pressure alarms if connected pre-pump and high } \\
\text { pressure alarms when connected post-pump) } \\
\text { Requires a RRT machine capable of adjusting alarm settings } \\
\text { Risk of air entrapment if access line is connected before centrifugal } \\
\text { pump } \\
\text { Flow turbulence with risk of hemolysis and thrombus formation } \\
\text { Generation of shunt within ECMO circuit } \\
\text { Recirculation }\end{array}$ \\
\hline
\end{tabular}

RRT renal replacement therapy, UF ultrafiltration

RRT access from the ECMO circuit (parallel system) [31, 32] (Table 3). In the absence of evidence-based data, practice is based on expert opinion, availability of machines, local expertise, and staff organization. A 2013 survey of 65 ECMO centers showed that $50.8 \%$ of centers used independent CRRT circuits while $21.5 \%$ used in-line hemofilter [24]. The results of a recent survey of ECMO centers in France and Switzerland are awaited.

\section{In-line hemofilter}

It is possible to provide RRT by incorporating a hemofilter into the ECMO circuit $[9,15,31]$ (Fig. 1a). The hemofilter is placed after the pump pre-oxygenator so that the oxygenator can trap air and clots. The positive pressure from the ECMO circuit will forward the blood flow through the hemofilter. Then, blood is returned from the filter to the ECMO circuit before the pump. The blood flow rate in the hemofilter is the difference between the total ECMO blood flow rate and the actual flow delivered to the patient, which is measured by placing an ultrasonic probe on the arterial return line from the ECMO circuit. This technique is mainly used for ultrafiltration via the SCUF mode. CVVH or CVVHD can be delivered by adding replacement fluid $(\mathrm{CVVH})$ or dialysis fluid (CVVHD) through standard infusion pumps. Ultrafiltration rate is regulated by connecting a standard infusion device to the effluent port of the hemofilter. However, the amount of removed fluid is less accurate and prone to error up to $800 \mathrm{ml} /$ day [34]. A more precise method is to weigh the actual volume of ultrafiltration using a scale or a volumetric measuring device but this method is laborintensive. Since hemofilters are not designed for use with high pressure systems and the maximal volume of the infusion pump is limited at $1 \mathrm{l} / \mathrm{h}$, convective and diffusive clearance are less effective than with CRRT using conventional membranes. The hemofilter blood flow rate can be adjusted via a stopcock or a flow-restrictor. Nevertheless, the generated turbulent flow might cause hemolysis and trigger thrombus formation. Most importantly, there is no pressure monitoring with this technique, which may lead to delayed detection of hemolysis, filter rupture or clot formation.

\section{Parallel system (independent RRT access)}

Setting up an independent RRT device is simple as it does not require ECMO circuit manipulation (Fig. 1b). Dose

(see figure on next page.)

Fig. 1 Options of combining extracorporeal membrane oxygenation (ECMO) and continuous renal replacement therapy (CRRT) circuits. a An in-line hemofilter is integrated into the ECMO circuit. Replacement fluid is directly administered into the ECMO circuit. Alternatively, dialysis fluid can be supplied in a counter-current position. Replacement/dialysis fluid rates and ultrafiltration rates can be controlled via infusion pumps. $\mathbf{b}$ The CRRT device is connected to the patient through a separate catheter independent of the ECMO circuit. c The access (inlet) and the return (outlet) lines of the CRRT device are connected before the centrifugal blood pump (low-pressure part) of the ECMO circuit. $\mathbf{d}$ Both the access and the return lines of the CRRT device are connected after the blood pump. eThe access line of the CRRT device is connected after the blood pump (high-pressure), while the CRRT return line is connected before the centrifugal blood pump. f The access line of the CRRT device is connected directly after the membrane oxygenator, while the return line is connected directly before the oxygenator 


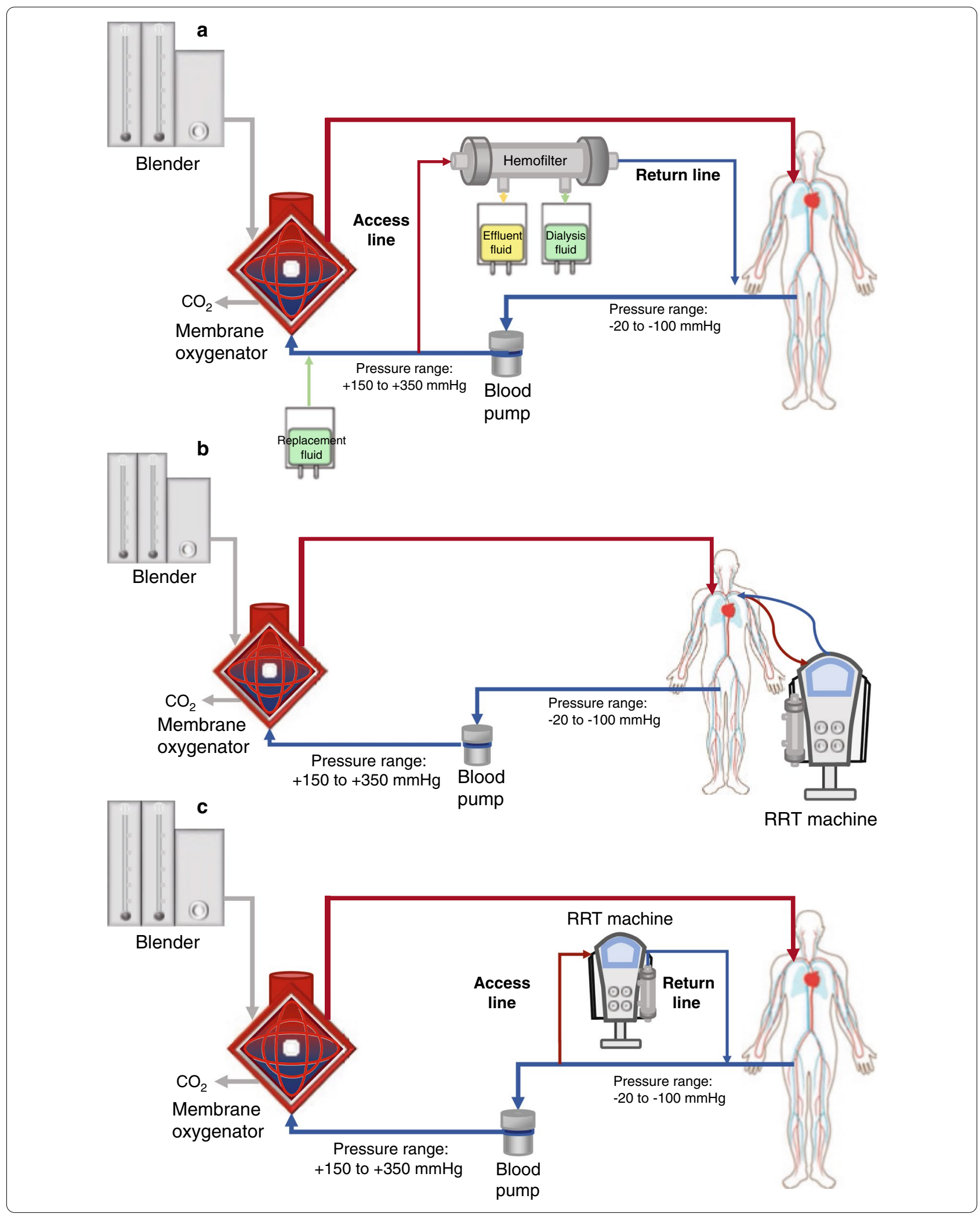




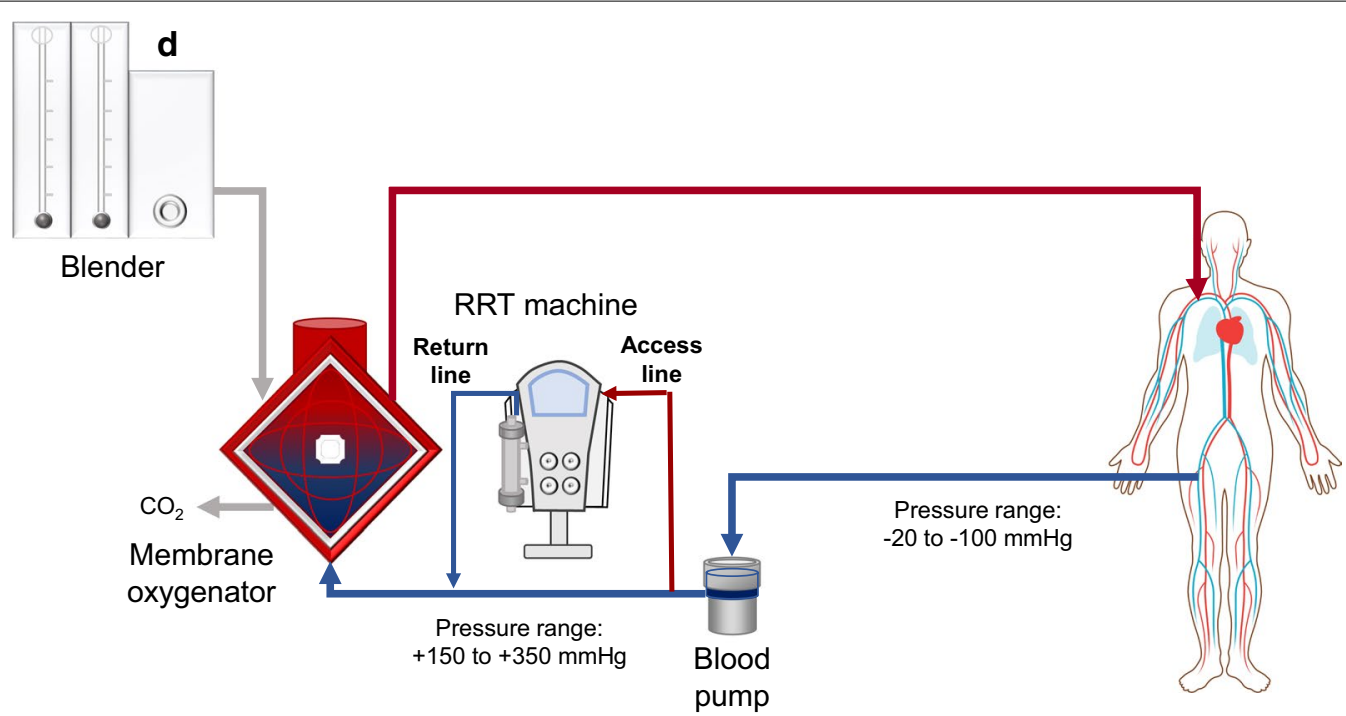

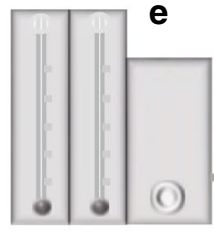

Blender

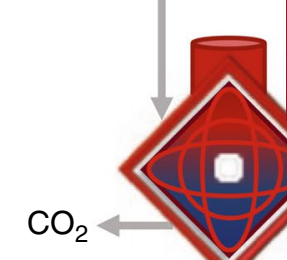

Membrane oxygenator

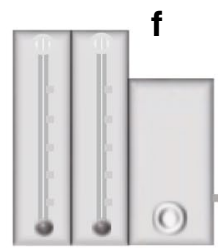

Blender
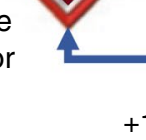

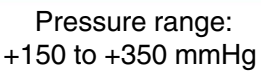

$$
\begin{aligned}
& \text { Blood } \\
& \text { pump }
\end{aligned}
$$

\section{RRT machine}
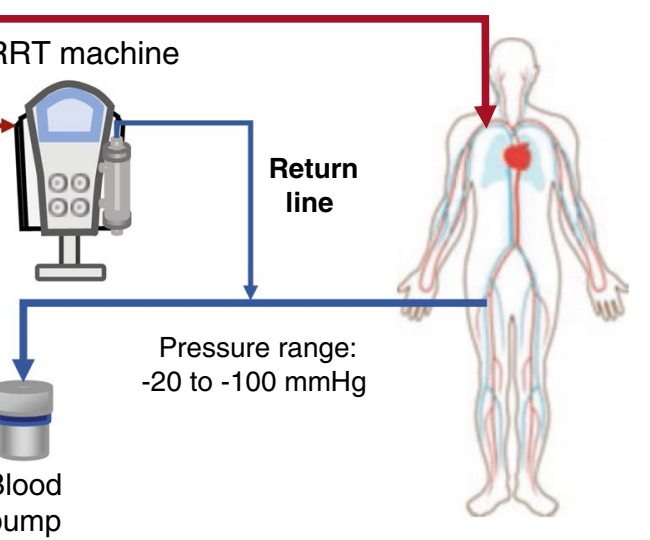

Pressure range:

-20 to $-100 \mathrm{mmHg}$

line

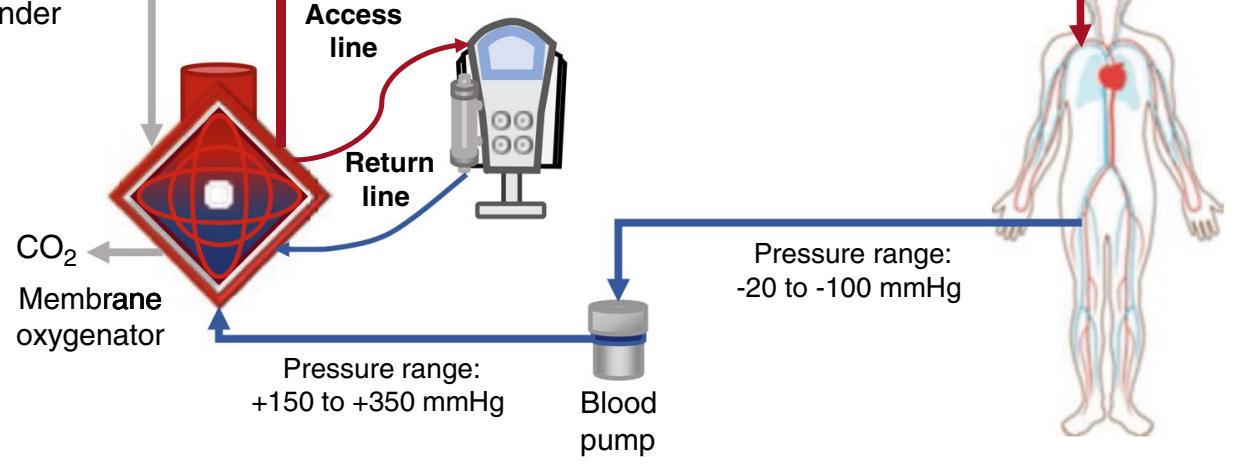

Fig. 1 continued 
and modality can be adjusted, and fluid balance can be controlled in a precise manner as per usual protocol. Regional anticoagulation can also be added and optimised to prolong filter longevity. However, the need to insert a separate vascular access whilst systemically anticoagulated poses a risk for line-related mechanical and infectious complications. This technique also requires an additional extracorporeal blood volume, which might interfere with ECMO performance $[9,15,31]$.

\section{Integrated system (combining RRT machine into the ECMO circuit)}

There are several ways to incorporate a RRT device into the ECMO circuit using two high-flow Luer lock threeway taps as connectors to the RRT access (inlet) line and return (outlet) line [9, 31, 33, 35] (Fig. 1c-f). The pressure before the ECMO pump is negative (range: -20 to $-100 \mathrm{mmHg}$ ) and post-pump is positive (range: +150 to $+350 \mathrm{mmHg}$ ), which might interfere with the RRT circuit. If a centrifugal pump is used, the RRT access line should be placed post-pump (either before or after the oxygenator) to avoid air entrapment (Fig. 1d, e). The RRT return line should be connected before the oxygenator (either pre- or post-pump) to avoid air embolism, clot formation and venous admixture. Careful attention should be paid to the inherently set pressure limits of the ECMO circuit and RRT devices from different manufacturers. The default access pressure of the RRT machine is typically negative. High post-pump pressure may trigger pressure alarms at the entry point of the RRT machine although current RRT machines can tolerate higher pressures or allow adjustment of alarm settings up to +350 to $+500 \mathrm{mmHg}$. To overcome the alarm limits of the RRT machine, a long monitoring extension line attached to the RRT access tubing or reducing the blood flow rates can help to lower the pressure from the ECMO circuit [8]. Another option is to use clamps on the connectors or flow restrictors placed outside the tubing to adjust the RRT circuit pressure on the access or, alternatively, on the return line to avoid extreme pressures [36]. However, this may cause turbulence in blood flow and trigger hemolysis or thrombosis. When withdrawing blood post-oxygenator and returning blood before pump, re-circulation in the RRT circuit (shunt within a shunt) and RRT underdosing may occur. Alternatively, the access and return lines may be safely connected through Luer locks immediately before and after the oxygenator to avoid pressure alarms (Fig. 1f).

Combining RRT into the ECMO circuit has several benefits. No additional vascular access is needed and complications related to line insertion are avoided. This method is more effective than using an in-line hemofilter and provides more precise ultrafiltration control and solute clearance by any modality of choice. Use of the heater on the CRRT device is optional. There is also no need for routine additional anticoagulation. However, every connection and disconnection requires support from an ECMO specialist/perfusionist and might pose a risk of air embolism/clot to both devices.

\section{Comparison of different techniques}

There are few studies comparing the efficacy between the different techniques. Compared with an in-line hemofilter technique, integrating a RRT machine into the ECMO circuit was shown to provide more accurate fluid management [37]. A recent study concluded that independent RRT access was associated with fewer effective sessions and shorter filter lives in comparison with the integrated system [38]. However, the average prescribed RRT dose was $40 \mathrm{ml} / \mathrm{kg} / \mathrm{h}$, which is higher than currently recommended. In addition, the CVVH modality was used with $33 \%$ of replacement fluid given pre-filter, which might result in a relatively high filtration fraction. Regional citrate anticoagulation was not used [39]. Another study also reported longer filter life for the integrated system compared with the parallel technique [35]. With regards to clearance, a recent study demonstrated similar efficacy for solute clearance and ultrafiltration between the parallel and the integrated methods [40].

\section{Technical aspects \\ Mediator removal}

Although raised cytokine concentrations have been demonstrated in patients with AKI receiving ECMO and might be implicated in multiorgan dysfunction [41], there is insufficient evidence to recommend blood purification therapy outside the setting of AKI for patients receiving ECMO. Therefore, the use of RRT and/or hemoadsorption with the sole intention of clearing proor anti-inflammatory mediators during ECMO is not recommended [9].

\section{Anticoagulation}

Systemic infusion of unfractionated heparin is the standard anticoagulation in patients receiving RRT and ECMO unless contraindicated. However, significant clotting or excessive bleeding precluding the use of systemic heparin may require the addition of regional citrate anticoagulation to ensure effective RRT delivery [42]. Nevertheless, significant citrate dilution might occur. If the RRT access line is connected from the post-oxygenator limb and the return line is connected to the pre-oxygenator limb, 
infused citrate will be partially delivered and mixed with pre-oxygenator blood. This may reduce clotting in the oxygenator. Calcium should be infused via a separate central venous access to reduce clotting in the system.

\section{Drug dosing}

ECMO and RRT can significantly alter the pharmacokinetics of medications such as antibiotics and sedatives, yet little is known about the optimal regimen for patients treated with both RRT and ECMO. Generally, ECMO increases the volume of distribution and reduces drug clearance. The ECMO circuit might act as a reservoir and redistribute the sequestered drug back into the patient leading to prolonged effects, especially of lipophilic medications with a large volume of distribution (e.g., voriconazole, propofol, fentanyl, midazolam) [8]. In contrast, the ECMO membrane and tubing may adsorb some drugs and reduce plasma concentrations. The presence of RRT increases the risk of both under- and over-dosing further. A preliminary analysis showed that standard dosing of meropenem (1 $\mathrm{g}$ 8-hourly) is likely to maintain sufficient trough concentrations $(>2 \mathrm{mg} / \mathrm{l})$ to treat highly susceptible gram-negative pathogens but might be inadequate for higher trough targets [43]. Individualizing drug regimens in patients receiving concomitant ECMO and RRT using therapeutic drug monitoring is suggested where possible until more pharmacokinetic data become available.

\section{Short-term outcomes}

AKI and RRT have been shown to be independently associated with mortality but it is uncertain whether they directly increase the risk of dying or merely represent the acuity and severity of the illness [19]. The pooled estimated hospital and/or 90-day mortality rates of patients with AKI and severe AKI requiring RRT while on ECMO were $62.0 \%$ and $68.4 \%$, respectively [6]. The likelihood of dying in hospital of ECMO patients receiving RRT is three times that of those without RRT [6]. Importantly, mortality has decreased by $>20 \%$ since 2016 compared with data from before 2015, possibly due to better patient selection, timing, and clinical application [44].

AKI requiring RRT is associated with other complications, including sepsis, need for fasciotomy/amputation, respiratory failure, intra-aortic balloon pump (IABP) usage, massive blood transfusion, and failure to wean from ECMO [45]. Acute respiratory failure can also be worsened following AKI due to fluid overload, pulmonary edema, increased inflammatory mediators and increased risk of intercurrent sepsis. Other risk factors for mortality include age, oliguria, AKI stage 3, RRT duration hypercapnia, high sequential organ failure assessment
(SOFA) score, blood loss, transfusion requirement, hemodynamic instability, liver failure, low Glasgow coma score, and fluid overload [7, 46, 47].

\section{Renal recovery and long-term outcomes}

The long-term renal prognosis in ECMO survivors is uncertain. Previous studies showed high rates of liberation from dialysis at hospital discharge $[4,48]$. However, only $42 \%$ of AKI stage 3 survivors had complete renal recovery [7]. In a cohort of post-cardiotomy patients with cardiogenic shock receiving VA-ECMO, all but 2 patients recovered from AKI stage 3 at 6 months [18]. However, it should be noted that creatinine at discharge might be falsely low due to loss of muscle mass and malnutrition following prolonged hospitalization. Therefore, low serum creatinine levels may lead to erroneous glomerular filtration rate (GFR) results and mislead clinicians, resulting in inappropriate drug dosing and inadequate follow-up.

It is established that AKI survivors are at increased risk for long-term mortality, end-stage kidney disease, chronic kidney disease (CKD), and poorer quality of life. However, only a few studies have explored the long-term outcomes of ECMO patients with AKI. In children, two large ECMO studies independently reported a 20-year experience and showed no incidence of end-stage kidney disease in the absence of primary renal disease $[38,48]$. In contrast, analysis of a VAECMO cohort of adult population showed an $85 \%$ incidence of major adverse kidney events, comprised death, end-stage kidney disease, and reduced GFR at 1 year [49].

Risk factors for 1-year major adverse kidney events included lower GFR at baseline, higher AKI stage at ECMO cannulation, and number of red blood cell transfusions. Moreover, the median GFR decline was $20 \mathrm{ml} /$ $\mathrm{min} / 1.73 \mathrm{~m}^{2}$, and half of AKI survivors had a GFR decline of more than $30 \%$. Decline of GFR by $>30 \%$ is associated with $>5$ times increased risk of end-stage kidney disease [50]. Therefore, the risk of serious long-term renal outcomes should not be underestimated in ECMO patients with AKI. Analysis of a national Taiwan database including 3200 adult patients receiving ECMO with up to 10-year follow-up data revealed higher rates of all- cause mortality, end-stage kidney disease and CKD in patients with RRT-requiring AKI compared with non-dialysis-requiring AKI patients [45]. Prolonged CRRT use ( $>7$ days vs. $\leq 6$ days) was associated with an increased risk of end-stage kidney disease, ventilator dependence, and readmission rate but not survival after discharge [51]. 


\section{Conclusion}

AKI is extremely common and associated with worse short-term and long-term outcomes in patients receiving ECMO, especially when RRT is required. The most common indication for RRT initiation in these patients is fluid control. RRT should be initiated when the anticipated demand from fluid overload and metabolic derangements exceeds the capacity of the kidneys to compensate. The modality and techniques of providing RRT in patients receiving ECMO depend on local practice and expertise. Provision of RRT as an armamentarium of multiorgan support therapy requires a multidisciplinary team engagement (such as intensivists, nephrologists, cardiologists, cardiac, thoracic and vascular surgeons, perfusionists, dedicated nurses, pharmacists, dietitians, and others) from admission, through ECMO cannulation and RRT initiation, until after discharge. Further research should determine the optimal technique to combine ECMO and RRT, optimal drug dosing and long-term renal prognosis.

\section{Acknowledgements}

The authors would like to thank the critical care team at Guy's \& St Thomas' Hospital for providing care to patients who need ECMO and renal replacement therapy.

\section{Authors' contributions}

$\mathrm{MO}$ and $\mathrm{NL}$ reviewed the existing literature. NL wrote the first draft. MO made edits to the draft. All authors read and approved the final draft.

\section{Funding}

No funding was received. Publications costs were funded by Dr Ostermann's research fund.

\section{Availability of data and materials}

Material used in this manuscript is available from the corresponding author at reasonable request.

\section{Declarations}

Ethics approval and consent to participate

Not applicable.

\section{Consent for publication}

Not applicable.

\section{Competing interests}

$\mathrm{MO}$ has received research funding and speaker honoraria from Fresenius Medical Care and Baxter. NL reports no conflict of interest.

\section{Author details}

'Department of Critical Care, King's College London, Guy's and St Thomas' NHS Foundation Trust, London, UK. ${ }^{2}$ Division of Nephrology and Excellence Centre for Critical Care Nephrology, King Chulalongkorn Memorial Hospital, Bangkok, Thailand. ${ }^{3}$ Critical Care Nephrology Research Unit, Chulalongkorn University, Bangkok, Thailand.

Published online: 31 August 2021

\section{References}

1. Thiagarajan RR, Barbaro RP, Rycus PT, McMullan DM, Conrad SA, Fortenberry JD, et al. Extracorporeal life support organization registry international report 2016. ASAIO J. 2017;63:60-7.

2. Combes A, Peek GJ, Hajage D, Hardy P, Abrams D, Schmidt M, et al. ECMO for severe ARDS: systematic review and individual patient data metaanalysis. Intensive Care Med. 2020;46:2048-57.

3. Gao S, Liu G, Yan S, Lou S, Gao G, Hu Q, et al. Outcomes from adult veno-arterial extracorporeal membrane oxygenation in a cardiovascular disease center from 2009 to 2019. Perfusion. 2021; https://doi.org/10. 1177/0267659121993365. [Epub ahead of print].

4. Deatrick KB, Mazzeffi MA, Galvagno SMJ, Boswell K, Kaczoroswki DJ, Rabinowitz RP, et al. Breathing life back into the kidney-continuous renal replacement therapy and veno-venous extracorporeal membrane oxygenation. ASAIO J. 2021;67:208-12.

5. Lafç G, Budak AB, Yener A, Cicek OF. Use of extracorporeal membrane oxygenation in adults. Heart Lung Circ. 2014;23:10-23.

6. Thongprayoon C, Cheungpasitporn W, Lertjitbanjong P, Aeddula NR, Bathini T, Watthanasuntorn K, et al. Incidence and impact of acute kidney injury in patients receiving extracorporeal membrane oxygenation: a meta-analysis. J Clin Med. 2019;8:981.

7. Delmas C, Zapetskaia T, Conil JM, Georges B, Vardon-Bounes F, Seguin T, et al. 3-month prognostic impact of severe acute renal failure under veno-venous ECMO support: importance of time of onset. J Crit Care. 2018;44:63-71.

8. Husain-Syed F, Ricci Z, Brodie D, Vincent JL, Ranieri VM, Slutsky AS, et al. Extracorporeal organ support (ECOS) in critical illness and acute kidney injury: from native to artificial organ crosstalk. Intensive Care Med. 2018;44:1447-59.

9. Joannidis M, Forni LG, Klein SJ, Honore PM, Kashani K, Ostermann M, et al. Lung-kidney interactions in critically ill patients: consensus report of the acute disease quality initiative(ADQI) 21 workgroup. Intensive Care Med. 2020;46:654-72.

10. Gurkan OU, O'Donnell C, Brower R, Ruckdeschel E, Becker PM. Differential effects of mechanical ventilatory strategy on lung injury and systemic organ inflammation in mice. Am J Physiol Lung Cell Mol Physiol. 2003;285:L710-8.

11. Murugan R, Wen X, Shah N, Lee M, Kong L, Pike F, et al. Plasma inflammatory and apoptosis markers are associated with dialysis dependence and death among critically ill patients receiving renal replacement therapy. Nephrol Dial Transp. 2014;29:1854-64.

12. Brower RG, Matthay MA, Morris A, Schoenfeld D, Thompson BT, Wheeler A. Ventilation with lower tidal volumes as compared with traditional tidal volumes for acute lung injury and the acute respiratory distress syndrome. N Engl J Med. 2000;342:1301-8.

13. Kilburn DJ, Shekar K, Fraser JF. The complex relationship of extracorporeal membrane oxygenation and acute kidney injury: Causation or association? Biomed Res Int. 2016;2016:1094296.

14. Ootaki C, Yamashita M, Ootaki Y, Kamohara K, Weber S, Klatte RS, et al. Reduced pulsatility induces periarteritis in kidney: role of the local reninangiotensin system. J Thorac Cardiovasc Surg. 2008;136:150-8.

15. Askenazi DJ, Selewski DT, Paden ML, Cooper DS, Bridges BC, Zappitelli M, et al. Renal replacement therapy in critically ill patients receiving extracorporeal membrane oxygenation. Clin J Am Soc Nephrol. 2012;7:1328-36.

16. Villa G, Katz N, Ronco C. Extracorporeal membrane oxygenation and the kidney. Cardiorenal Med. 2015;6:50-60.

17. Ricci Z, Pezzella C, Romagnoli S, lodice F, Haiberger R, Carotti A, et al. High levels of free hemoglobin in neonates and infants undergoing surgery on cardiopulmonary bypass. Interact Cardiovasc Thorac Surg. 2014;19:183-7.

18. Lepère V, Duceau B, Lebreton G, Bombled C, Dujardin O, Boccara L, et al. Risk factors for developing severe acute kidney injury in adult patients with refractory postcardiotomy cardiogenic shock receiving venoarterial extracorporeal membrane oxygenation. Crit Care Med. 2020;48:e715-21.

19. Lee SW, Yu MY, Lee H, Ahn SY, Kim S, Chin HJ, et al. Risk factors for acute kidney injury and in-hospital mortality in patients receiving extracorporeal membrane oxygenation. PloS ONE. 2015;10:e0140674.

20. Salis S, Mazzanti W, Merli G, Salvi L, Tedesco CC, Veglia F, et al. Cardiopulmonary bypass duration is an independent predictor of morbidity and mortality after cardiac surgery. J Cardiothorac Vasc Anesth. 2008;22:814-22. 
21. Lou S, MacLaren G, Best D, Delzoppo C, Butt W. Hemolysis in pediatric patients receiving centrifugal-pump extracorporeal membrane oxygenation: prevalence, risk factors, and outcomes. Crit Care Med. 2014;42:1213-20.

22. Antonucci E, Lamanna I, Fagnoul D, Vincent JL, De Backer D, Silvio TF. The impact of renal failure and renal replacement therapy on outcome during extracorporeal membrane oxygenation therapy. Artif Organs. 2016:40:746-54.

23. Swaniker F, Kolla S, Moler F, Custer J, Grams R, Barlett R, et al. Extracorporeal life support outcome for 128 pediatric patients with respiratory failure. J Pediatr Surg. 2000;35:197-202.

24. Fleming GM, Askenazi DJ, Bridges BC, Cooper DS, Paden ML, Selewski DT, et al. A multi-center international survey of renal supportive therapy during ECMO: the kidney intervention during extracorporeal membrane oxygenation (KIDMO) group. ASAIO J. 2012;58:407-14.

25. Bagshaw SM, Wald R, Adhikari NKJ, Bellomo R, da Costa BR, Dreyfuss D, et al. Timing of initiation of renal-replacement therapy in acute kidney injury. N Engl J Med. 2020;383:240-51.

26. Barbar SD, Clere-Jehl R, Bourredjem A, Hernu R, Montini F, Bruyère R, et al. Timing of renal-replacement therapy in patients with acute kidney injury and sepsis. N Engl J Med. 2018;379:1431-42.

27. Gaudry S, Hajage D, Schortgen F, Martin-Lefevre L, Pons B, Boulet E, et al. Initiation strategies for renal-replacement therapy in the intensive care unit. N Engl J Med. 2016;375:122-33.

28. Gaudry S, Hajage D, Schortgen F, Martin-Lefevre L, Verney C, Pons B, et al. Timing of renal support and outcome of septic shock and acute respiratory distress syndrome. A post hoc analysis of the AKIKI randomized clinical trial. Am J Respir Crit Care Med. 2018;198:58-66.

29. Paek JH, Park S, Lee A, Park S, Chin HJ, Na KY, et al. Timing for initiation of sequential continuous renal replacement therapy in patients on extracorporeal membrane oxygenation. Kidney Res Clin Pract. 2018;37:239-47.

30. Ostermann M, Joannidis M, Pani A, Floris M, De Rosa S, Kellum JA, et al. Patient selection and timing of continuous renal replacement therapy. Blood Purif. 2016;42:224-37.

31. Ostermann M, Connor M Jr, Kashani K. Continuous renal replacement therapy during extracorporeal membrane oxygenation: Why, when and how? Curr Opin Crit Care. 2018;24:493-503.

32. Kashani K, Ostermann M. Optimizing renal replacement therapy for patients who need extracorporeal membrane oxygenation: crosstalk between two organ support machines. BMC Nephrol. 2019;20:404.

33. Seczyńska B, Królikowski W, Nowak I, Jankowski M, Szułdrzyński K, Szczeklik W. Continuous renal replacement therapy during extracorporeal membrane oxygenation in patients treated in medical intensive care unit: technical considerations. Ther Apher Dial. 2014;18:523-34.

34. Sucosky P, Dasi LP, Paden ML, Fortenberry JD, Yoganathan AP. Assessment of current continuous hemofiltration systems and development of a novel accurate fluid management system for use in extracorporeal membrane oxygenation. ASME J Med Devices. 2008;2:0350022008.

35. Santiago MJ, Sánchez A, López-Herce J, Pérez R, del Castillo J, Urbano $J$, et al. The use of continuous renal replacement therapy in series with extracorporeal membrane oxygenation. Kidney Int. 2009;76:1289-92.

36. Na SJ, Choi HJ, Chung CR, Cho YH, Jang HR, Suh GY, et al. Using additional pressure control lines when connecting a continuous renal replacement therapy device to an extracorporeal membrane oxygenation circuit. BMC Nephrol. 2018;19:369.

37. Symons JM, McMahon MW, Karamlou T, Parrish AR, McMullan DM. Continuous renal replacement therapy with an automated monitor is superior to a free-flow system during extra-corporeal life support. Pediatr Crit Care Med. 2013;14:e404-8.

38. Meyer RJ, Brophy PD, Bunchman TE, Annich GM, Maxvold NJ, Mottes TA, et al. Survival and renal function in pediatric patients following extracorporeal life support with hemofiltration. Pediatr Crit Care Med. 2001;2:238-42.

39. de Tymowski C, Desmard M, Lortat-Jacob B, Pellenc Q, Alkhoder S, Alouache A, et al. Impact of connecting continuous renal replacement therapy to the extracorporeal membrane oxygenation circuit. Anaesth Crit Care Pain Med. 2018;37:557-64.

40. Worku B, Khin S, Gaudino M, Gambardella I, lannacone E, Ebrahimi H, et al. Renal replacement therapy in patients on extracorporeal membrane oxygenation support: who and how. Int J Artif Organs. 2020; https://doi. org/10.1177/0391398820980451. [Epub ahead of print].

41. Liu CH, Kuo SW, Ko WJ, Tsai PR, Wu SW, Lai CH, et al. Early measurement of IL-10 predicts the outcomes of patients with acute respiratory distress syndrome receiving extracorporeal membrane oxygenation. Sci Rep. 2017;7:1021.

42. Shum HP, Kwan AM, Chan KC, Yan WW. The use of regional citrate anticoagulation continuous venovenous hemofiltration in extracorporeal membrane oxygenation. ASAIO J. 2014;60:413-8.

43. Shekar K, Fraser JF, Taccone FS, Welch S, Wallis SC, Mullany DV, et al. The combined effects of extracorporeal membrane oxygenation and renal replacement therapy on meropenem pharmacokinetics: a matched cohort study. Crit Care. 2014;18:565.

44. Mitra S, Ling RR, Tan CS, Shekar K, MacLaren G, Ramanathan K. Concurrent use of renal replacement therapy during extracorporeal membrane oxygenation support: a systematic review and meta-analysis. J Clin Med. 2021;10:241.

45. Chen SW, Lu YA, Lee CC, Chou AH, Wu VC, Chang SW, et al. Long-term outcomes after extracorporeal membrane oxygenation in patients with dialysis-requiring acute kidney injury: a cohort study. PLoS ONE. 2019;14:e0212352.

46. Haneya A, Diez C, Philipp A, Bein T, Mueller T, Schmid C, et al. Impact of acute kidney injury on outcome in patients with severe acute respiratory failure receiving extracorporeal membrane oxygenation. Crit Care Med. 2015:43:1898-906.

47. Schmidt M, Bailey M, Kelly J, Hodgson C, Cooper DJ, Scheinkestel C, et al. Impact of fluid balance on outcome of adult patients treated with extracorporeal membrane oxygenation. Intensive Care Med. 2014;40:1256-66.

48. Paden ML, Warshaw BL, Heard ML, Fortenberry JD. Recovery of renal function and survival after continuous renal replacement therapy during extracorporeal membrane oxygenation. Pediatr Crit Care Med. 2011;12:153-8.

49. Vinclair C, De Montmollin E, Sonneville R, Reuter J, Lebut J, Cally R, et al. Factors associated with major adverse kidney events in patients who underwent veno-arterial extracorporeal membrane oxygenation. Ann Intensive Care. 2020;10:44.

50. Coresh J, Turin TC, Matsushita K, Sang Y, Ballew SH, Appel LJ, et al. Decline in estimated glomerular filtration rate and subsequent risk of end-stage renal disease and mortality. JAMA. 2014;311:2518-31.

51. Kuo G, Chen SW, Fan PC, Wu VC, Chou AH, Lee CC, et al. Analysis of survival after initiation of continuous renal replacement therapy in patients with extracorporeal membrane oxygenation. BMC Nephrol. 2019;20:318.

\section{Publisher's Note}

Springer Nature remains neutral with regard to jurisdictional claims in published maps and institutional affiliations. 